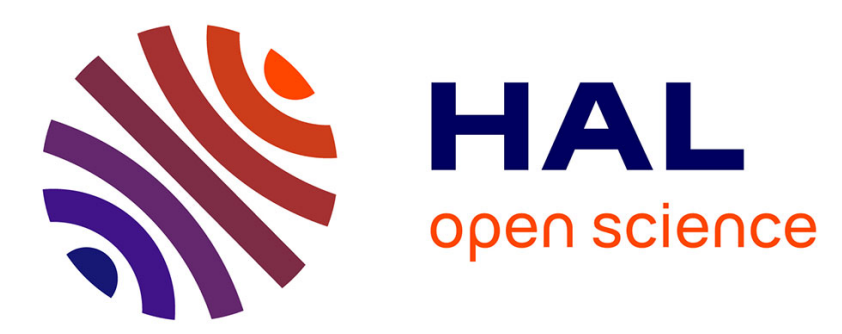

\title{
LOADING AND RADIATION EFFECTS IN PLASMA JET MODELLING
}

P. Proulx, J. Mostaghimi, M. Boulos

\section{To cite this version:}

P. Proulx, J. Mostaghimi, M. Boulos. LOADING AND RADIATION EFFECTS IN

PLASMA JET MODELLING. Journal de Physique Colloques, 1990, 51 (C5), pp.C5-263-C5-270. 10.1051/jphyscol:1990532 . jpa-00230839

\section{HAL Id: jpa-00230839 https://hal.science/jpa-00230839}

Submitted on 1 Jan 1990

HAL is a multi-disciplinary open access archive for the deposit and dissemination of scientific research documents, whether they are published or not. The documents may come from teaching and research institutions in France or abroad, or from public or private research centers.
L'archive ouverte pluridisciplinaire HAL, est destinée au dépôt et à la diffusion de documents scientifiques de niveau recherche, publiés ou non, émanant des établissements d'enseignement et de recherche français ou étrangers, des laboratoires publics ou privés. 
COLLOQUE DE PHYSIQUE

Colloque C5, supplément au $\mathrm{n}^{\circ} 18$, Tome 51, 15 septembre 1990

LOADING AND RADIATION EFFECTS IN PLASMA JET MODELLING

P. PROULX, J. MOSTAGHIMI and M.I. BOULOS

Centre de Recherche en Technologie des Plasmas (CRTP), Département de Génie Chimique, Université de Sherbrooke, Sherbrooke, (Québec) Canada JIK-2RI

Résumé - L'effet de l'interaction plasma-particules et de la présence de vapeurs métalliques provenant de l'évaporation des particules est étudié à l'aide d'un modèle mathématique. On trouve que le chauffage des particules ainsi que l'augmentation du rayonnement du aux vapeurs métalliques provoquent un refroidissement très important du plasma. La taille des particules a un effet déterminant sur ces deux phénomènes.

Abstract - The plasma-particle interaction and the effect of the presence of metallic vapors from the evaporating particles is studied using a mathematical model. It is found that the particle heating and the increase in radiative losses due to the metallic vapors are responsible for the important cooling of the plasma. The particle size is a critical parameter for these two effects.

\section{Lintroduction}

In a d.c. plasma jet, the size of the hot luminous core is significantly smaller than in induction RF plasmas of the same power level. Even if the maximum temperatures may be higher in d.c. plasmas, radiation usually plays a minor role in the overall energy balance of the jet. However, in view of recent studies on the radiative power of plasmas in the presence of metallic vapours/1-2/, it seems that even in plasma jets the increased radiative losses may have a significant effect on the associated temperature fields. Essoltani et al/1/have demonstrated that iron vapors in an argon plasma increases the radiative losses of the plasma by orders of magnitude even for small iron concentrations.

The objective of this work is to study how the presence of metallic particles and their vapours affect the temperature and flow fields in a d.c. plasma jet. The proposed mathematical model takes into account plasma-particle interaction, due the direct exchange of heat between the plasma and the particles, as well as the local cooling of the plasma jet due to the increased radiative losses in the presence of evaporating metal particles.

\section{The model}

\subsection{The plasma equations}

This model of the free plasma jet is based on the following assumptions:

- Axisymmetric system of coordinates

- Steady state turbulent boundary layer flow

- Negligible density fluctuations 
Based on these assumptions the time averaged conservation equations can be written as follows: Continuity:

$$
\frac{\partial}{\partial z} \rho \bar{u}+\frac{1}{r} \frac{\partial}{\partial r} r \rho \bar{v}=0
$$

Axial momentum:

$$
\rho \bar{u} \frac{\partial \bar{u}}{\partial z}+\rho \bar{v} \frac{\partial \bar{u}}{\partial r}=\frac{1}{r} \frac{\partial}{\partial r} r \mu_{e f f} \frac{\partial \bar{u}}{\partial r}+S_{p}^{M_{z}}
$$

Energy:

$$
\rho \bar{u} \frac{\partial \bar{h}}{\partial z}+\rho \bar{v} \frac{\partial \bar{h}}{\partial r}=\frac{1}{r} \frac{\partial}{\partial r} r \Gamma_{e f f_{h}} \frac{\partial \bar{h}}{\partial r}+S_{p}^{E}+Q_{r}
$$

Species:

$$
\rho \bar{u} \frac{\partial \bar{\omega}_{a}}{\partial z}+\rho \bar{v} \frac{\partial \bar{\omega}_{a}}{\partial r}=\frac{1}{r} \frac{\partial}{\partial r} r \Gamma_{\alpha f f} \frac{\partial \bar{\omega}_{a}}{\partial r}+S_{p}^{a}
$$

The subscript a refers to the species evaporated from the particles injected into the plasma jet. The plasma-particle interaction terms, $S_{p}^{M_{z}}, S_{p}^{E}, S_{p}^{a}$ are formulated in section 2.3.

The turbulence model used is the simple mixing length model. The effective transport coefficient are:

$$
\begin{gathered}
\mu_{e f f}=\mu+\mu_{T} \\
\Gamma_{e f f_{h}}=\frac{k}{C_{p}}+\frac{\mu_{T}}{\sigma_{h}} \\
\Gamma_{e f f_{e}}=\rho D+\frac{\mu_{T}}{\sigma_{a}}
\end{gathered}
$$

with the turbulent viscosity evaluated from:

$$
\mu_{T}=\rho l_{m}^{2}\left|\frac{\partial \bar{u}}{\partial r}\right|
$$

The radiative source term $Q_{r}$ in the energy equation(3) is a strong function of the temperature and of the concentration of metallic vapor. The data used for radiation of the plasma in the presence of iron vapors are based on the theoretical calculations of Essoltani et al/1/. Since the plasma jet is turbulent, the effect of the variation of the transport properties with the concentration of iron will not affect the flow, therefore the thermal conductivity and viscosity used were those of pure argon.

\subsection{The radiative losses of an argon plasma in the presence of iron vapors}

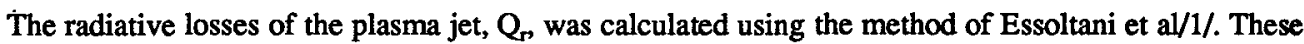
authors use the method of the net emission coefficient, proposed by Lowke/3/, to calculate the net emission coefficient of an isothermal, homogeneous plasma column. In their calculations they included more than 3500 atomic and ionic iron lines, over 400 argon lines and included broadening mechanisms such as Doppler, Stark, resonance and Van der Waals effects. The resulting net emission coefficient is a function of the temperature, iron concentration, and distance of self-absorption. The authors found that self-absorption was severe within the first mm of the radiation path, due to the strong self-absorption of the resonance lines of argon. After this first millimeter the argon-iron plasma can be approximated as transparent with reasonable accuracy. Therefore in the present calculations, the net emission coefficient used was calculated with an absorption path of $1 \mathrm{~mm}$ and the plasma was treated as transparent. Figure 1 shows the radiative losses, $Q$ used in the present calculations. 


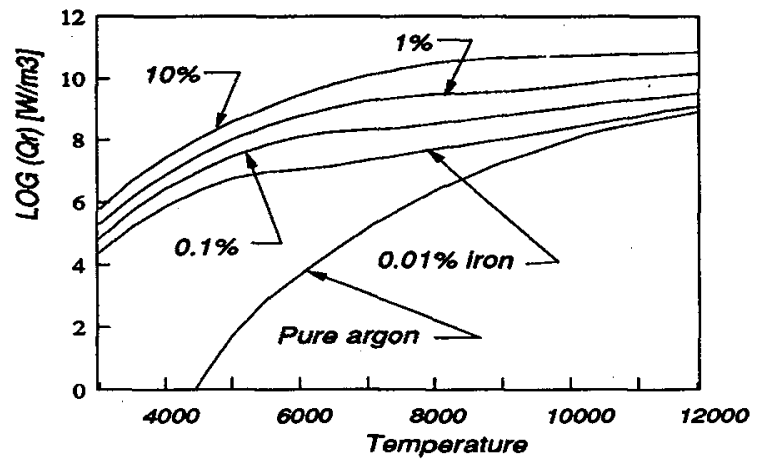

Figure 1. Radiative losses of an argon plasma in the presence of iron vapors, after Essoltani et al./1\%.

\subsection{The single particle trajectorv equations}

Assuming that the only significant force acting on the particle is the drag force, one can express the single particle trajectory equations as:

$$
\begin{aligned}
& \frac{d u_{p}}{d t}=-\frac{3}{4} C_{D}\left(u_{p}-u\right) U_{R}\left(\frac{\rho}{\rho_{p} d_{p}}\right) \\
& \frac{d v_{p}}{d t}=-\frac{3}{4} C_{D}\left(v_{p}-v\right) U_{R}\left(\frac{\rho}{\rho_{p} d_{p}}\right)
\end{aligned}
$$

And from an energy balance on the particle:

$$
Q_{p}=\pi d_{p}^{2} h_{c}\left(T-T_{p}\right)-\pi d_{p}^{2} \sigma_{s} \varepsilon_{p}\left(T_{p}^{4}-T_{A}^{4}\right)
$$

Where $Q_{p}$ is the net heat transfer rate to the particle. Neglecting internal heat conduction in the particle and assuming that a particle remains at a constant temperature during melting and vaporization, the particle temperature history will be governed by the following equations:

$$
Q_{p}=\left\{\begin{array}{lr}
\left(\frac{\pi}{6} \rho_{p} d_{p}^{3} C_{p p}\right) \frac{d T_{p}}{d t} & T<T_{m} \vee T_{m}<T<T_{b} \\
\left(\frac{\pi}{6} \rho_{p} d_{p}^{3} H_{m}\right) \frac{d X_{p}}{d t} & T=T_{m} \\
\left(-\frac{\pi}{2} \rho_{p} d_{p}^{2} H_{b}\right) \frac{d d_{p}}{d t} & T=T_{b}
\end{array}\right.
$$

The transport correlations for the drag coefficient and the Nusselt number are determined from the relations given in $/ 4 /$. Correction for the strong property variation and rarefaction or Knudsen effect are taken into account according to the work of Chen and Pfender/5-7/ and McKelliget et al/8/.

\subsection{The plasma-particle interaction model}

\subsubsection{The source terms}

The plasma and the particles are coupled using the PSI-Cell algorithm of Crowe et al/9/and used in plasma flows by Proulx/10/. The source terms are expressed using the particle concentration, defined as:

$$
C=\frac{N \tau}{V}
$$


Where $\mathrm{N}$ is the rate of particle injection, $\tau$ is the residence time in a given control volume of volume $\mathrm{V}$. The general source term for a given particle and a given control volume is therefore:

$$
S_{p}^{\dagger}=C \frac{\Delta\left(m_{p} \phi\right)}{\tau}
$$

One of the advantages of this PSI-Cell algorithm is the flexibility of the method, which can easily include statistical distributions of the particles. In this study, distributions of particle size $\left(n_{\mathbb{d}}\right)$, injection position $\left(n_{\mathrm{r}}\right)$ and injection velocity $\left(n_{v}\right)$ are used to represent the stochastic nature of the powders trajectories in the jet. The effect of the turbulence on the particles trajectories $\left(n_{\mathfrak{v}}\right)$ is also included. The total source/sink term for a given control volume and for an intensive variable $\phi$ will therefore be:

$$
S_{p}^{\phi}=\sum_{n_{1}} \sum_{m_{p}} \sum_{n_{v}} \sum_{n_{t}} C \frac{\Delta\left(m_{p} \phi\right)}{\tau}
$$

\subsubsection{Particle turbulent dispersion}

The turbulent motion of the gas in a gas-particle flow is known to disperse the particles. This dispersion depends on the turbulence properties of the gas and on the physical properties of the particles, and is a complex phenomena. In the present work the turbulent dispersion of the particles is taken into account according to the work of Shuen et al/11/.

This model is suited for applications involving dilute gas-solid systems. Typically, the local velocity of the gas is divided into a time averaged and a fluctuating velocity component which is determined from the local intensity of turbulence. To take into account the effect of the fluctuation of the flow on the particles, their trajectories are integrated in the flow field under the influence of the turbulent eddies. A large number of particles trajectories need to be evaluated with the same initial conditions to give a good statistical representation of the gas-solid system.

\subsubsection{Effect of the particles on turbulence}

The influence of the particles of the turbulence characteristics has been taken into account using the model of Abramovitch $/ 12 /$ which expresses the turbulent viscosity of the gas-particle jet as:

$$
\mu_{t}^{\prime}=\frac{\mu_{t}}{1+\frac{p_{d}}{p}}
$$

where $\mu_{t}$ is the turbulent viscosity of the gas. $\frac{p_{d}}{p}$ is the ratio of the apparent density to that of the gas.

\subsection{Numerical solution}

The resulting parabolic partial differential equations, for the plasma jet equations, and ordinary differential equations for the particle trajectories and temperature history are solved using appropriate numerical techniques. An implicit marching technique is used to solve the plasma model, with a total of 72 points in the radial direction and 40 in the axial direction. The particles equations are solved with a Runge-Kutta technique.

\section{Results and discussion}

The diameter of the plasma torch, $D_{0}$ is $8 \mathrm{~mm}$, the total power in the gas is $10 \mathrm{~kW}$ and the plasma mass flow is $1 \mathrm{~g} / \mathrm{s}$ (38 SLPM) for all the calculations presented in the following discussion.

\subsection{Pure argon olasma iet}

The effect of the radiative losses on the argon plasma jet is presented in Figure 2. We observe only a small influence of the radiative losses on the temperature profile along the centerline of the jet with an even smaller influence on the corresponding velocity profile. The total power lost by radiation in this case is $200 \mathrm{~W}$, which represents only $2 \%$ of the total power input. As expected the radiative losses occur primarily in the high 
temperature core of the plasma jet. Below $9000 \mathrm{~K}$ the radiative losses for pure argon jet are negligible. As noted in the introduction the small contribution of the radiation is partly due to the small size of the high temperature core of the plasma jet.

\subsection{Effect of the evaporation of small iron particles}

Calculations are repeated for the same conditions as in the previous section except for the presence of small iron particles injected in the plasma jet with different mass flow rates of 0.1 to $5 \mathrm{~g} / \mathrm{min}$. These are relatively small in comparison with the argon gas flow rate of $1 \mathrm{~g} / \mathrm{s}(60 \mathrm{~g} / \mathrm{min})$. The iron particles are assumed to have a very narrow size distribution, with a mean diameter of $15 \mu \mathrm{m}$ and a standard deviation of $0.1 \mu \mathrm{m}$. They are injected radially into the plasma jet at a velocity of $30 \mathrm{~m} / \mathrm{s}$. For each run 500 trajectories are sufficient for a good statistical accuracy, when turbulent dispersion of the particles is taken into account.

a)

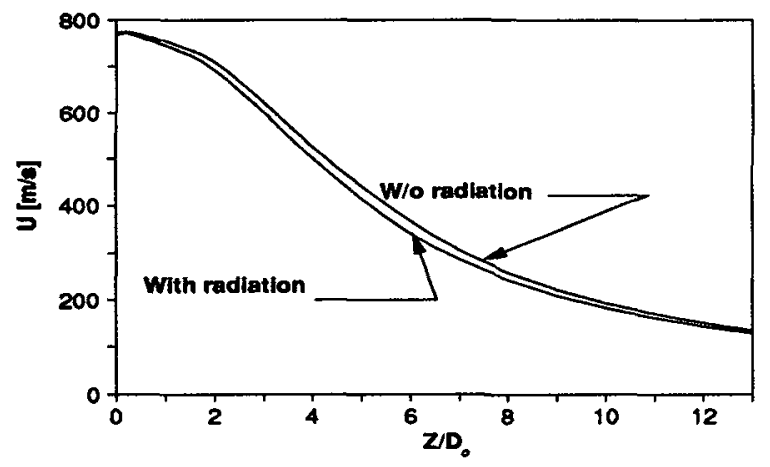

b)

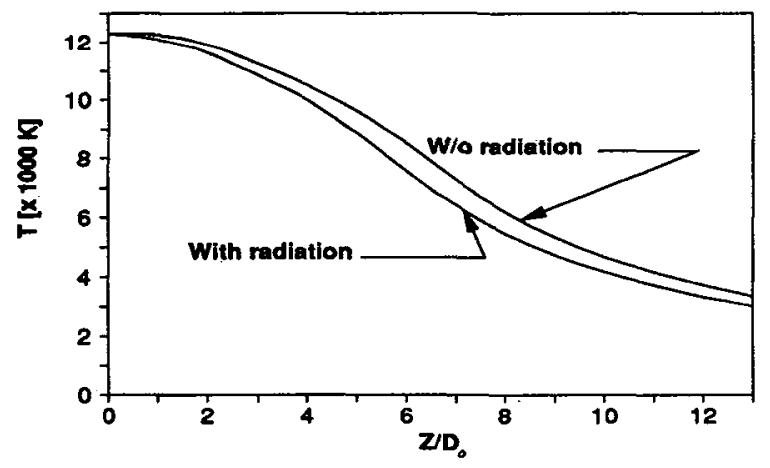

Figure 2 Centerline a)velocity and b) temperature profiles for an argon plasma jet with and without the radiative losses.

\begin{tabular}{|c|c|}
\hline $\begin{array}{c}\text { Iron powder mass } \\
\text { feed rate }\end{array}$ & \% evaporation \\
\hline 0.1 & 48 \\
0.5 & 46 \\
1 \\
2 & 44 \\
3 & 41 \\
5 & 39 \\
\hline
\end{tabular}

Table 1. Evaporation of the iron powders with increased loading 
Table 1 shows that with the increase of the powder mass feed rate from 0.1 to $5 \mathrm{~g} / \mathrm{min}$ the percentage of the powder evaporated decreases from $48 \%$ to $36 \%$. Clearly this is due to the influence of the vapors on the flow and temperature fields of the plasma jet. On Figure 3 the power loss from the plasma jet to heat and evaporate the particles, and heating the vapor to the plasma temperature, is plotted as a function of the powder feed rate. Superposed on the same figure for comparison, is the corresponding total radiative losses from the plasma jet to the surrounding due to the presence of the metal vapor. Radiative losses are obviously predominant in this case, representing $11 \%$ of the total plasma power in the presence of only $1 \mathrm{~g} / \mathrm{min}$ of iron and $22 \%$ in the presence of $5 \mathrm{~g} / \mathrm{min}$.

On Figure 4 we observe that the velocity and temperature on the axis of the plasma jet are decreased due to the augmented radiative losses. The effect is direct on the temperature fields and the cooling of the plasma results in lower velocities of the plasma gas. For a relatively small particle loading of $5 \mathrm{~g} / \mathrm{min}$ at an axial position of $40 \mathrm{~mm}$, i.e. 5 diameters from the discharge of the jet, the temperature on the axis of the plasma jet is approximately $5000 \mathrm{~K}$ while the pure argon plasma was almost $10000 \mathrm{~K}$ !

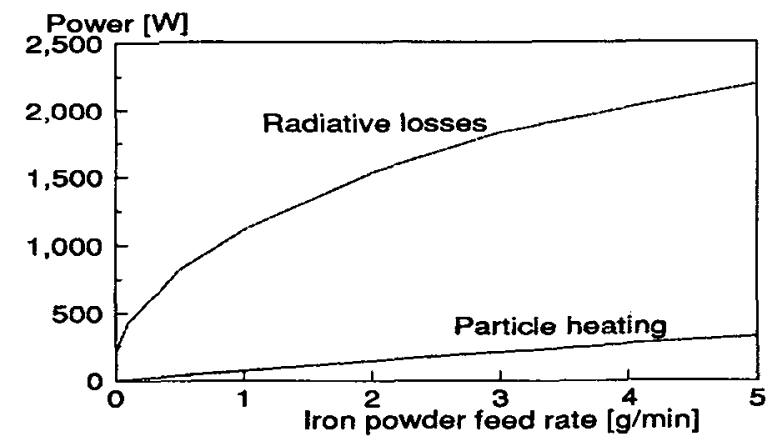

Figure 3. Power loss due to particle heating and radiative energy losses from the plasma as a function of the iron powder feed rate.

a)

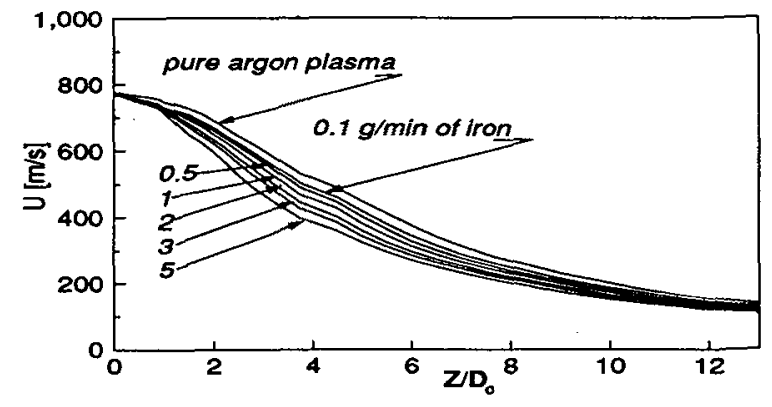

b)

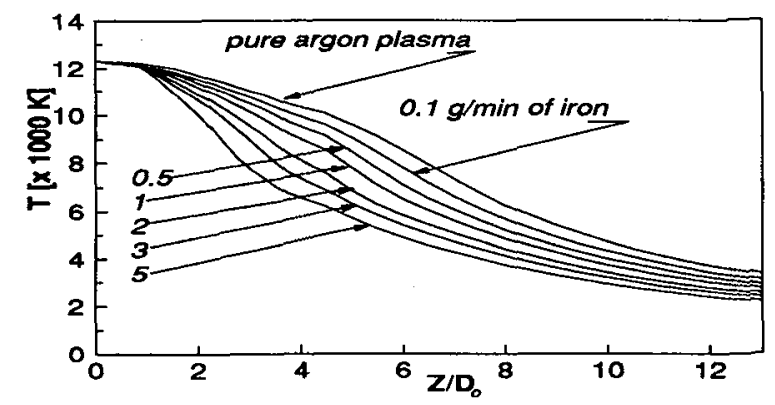

Figure 4 Centerline a)velocity and b) temperature profiles for an argon plasma jet in the presence of iron powder at different feed rates. 


\subsection{Importance of the radial iniection velocity of the particles}

For the same iron particles diameter of $15 \mu \mathrm{m}$, and a mass feed rate of $5 \mathrm{~g} / \mathrm{min}$, calculations are carried out with different radial injection velocities. Figure 5 presents the results obtained as the power lost from the plasma to heat and vaporize the particles and that lost from the plasma as radiation to the surroundings as a function of the radial particle injection velocity. As expected, when the velocity of the injected particles is increased the particle heating and evaporation is first increased due to the better penetration and the increased residence time of the particles in the hot zone of the plasma, with the further increase of the particle injection velocity and optimum is reached beyond which the particle heating and evaporation decreases. For the relatively small particle diameter considered in the present study, radiative energy losses from the plasma caused by the metal vapor cloud are obviously the predominant energy loss mechanism of the plasma jet.

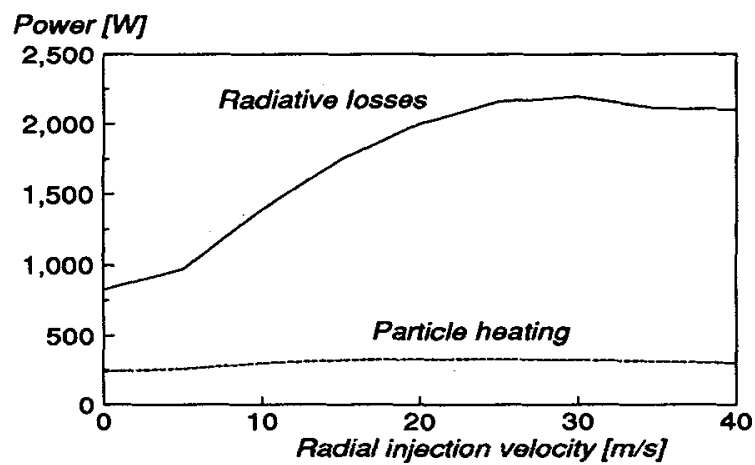

Figure 5. Effect of the particle injection velocity on the power losses from the plasma for particle heating and radiation to the surroundings.

\subsection{Importance of the particle size on the plasma-particle interaction}

As the size of the particles injected in the plasma jet are changed, so is the overall interaction between the particles and the plasma. When small particles are injected in the plasma, the strong and rapid evaporation of the iron in the hot core of the plasma increases significantly the radiative losses of the plasma jet. With larger particles on the other hand, the evaporation of the particles may be less important and therefore the radiation will play a minor role in the plasma-particle interaction. Figure 6 summarizes the effect of the particle size and loading on the direct particle heating and on the plasma radiation. We observe that particles $45 \mu \mathrm{m}$ in diameter have a much smaller effect on the plasma jet even at loadings as high as $40 \mathrm{~g} / \mathrm{min}$. For these large particles however, the power needed for particle heating, melting and vaporization is as important as the increase in plasma radiation due to the presence of the iron vapors.

\section{Conclusions}

The results presented in this paper underline the importance of direct plasma-particle interaction, which can be taken into account by the PSI-Cell model. These are shown for the case of a turbulent d.c. plasma jet to have a strong influence on the temperature and velocity fields. It also demonstrates clearly that the presence of metallic vapors can drastically increase the radiative cooling of the plasma. In applications where even a small fraction of the metallic powders evaporate in the plasma, the local cooling due to the increase in radiative losses limitates the amount of plasma heat available for the particles and therefore decreases largely the efficien. 
a)

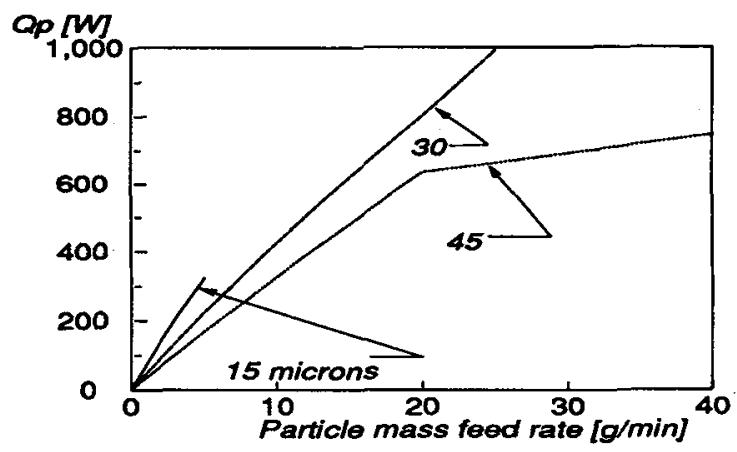

b)

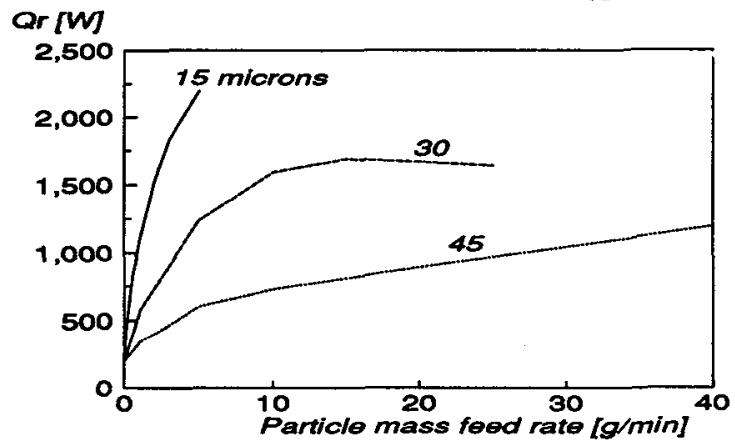

Figure 6. Power loss from the plasma jet due to a) radiative losses, b) particle heating as a function of the mean diameter and mass feed rate of the iron powders.

\section{Acknowledgements}

The authors gratefully acknowledge the financial support of the Natural Sciences and Engineering Research Council of Canada (NSERC) and the Fonds pour la Formation et l'Aide à la Recherche (FCAR) du Québec.

\section{References}

/1/Essoltani A., Proulx P., Boulos M.I., Gleizes A., to be published in JAAS, (1990).

12/ Proulx P., Mostaghimi J.T., Boulos M.I., to be published Int. J. Heat Mass Transfer, (1990).

13/ Lowke J.J., J. Quant. Spectrosc. Radiat. Transfer, 14, 111, 1974

14/ Proulx P, Mostaghimi J.T., Boulos M.I., Int. J. Heat Mass Transfer, Vol. 28; p. 1327, (1985).

15/ Chen X., Pfender E., Plasma Chem. Plasma Process., Vol 2, No 3, p. 293, (1982)

16/ Chen X., Pfender E., Plasma Chem. Plasma Process., Vol 2, No 2, p. 185, (1982)

$\Pi /$ Chen X., Pfender E., Plasma Chem. Plasma Process., Vol 3, No 1, p. 97, (1983)

18/ McKelliget J., Szekely J., Vardelle M., Fauchais P., Plasma Chem. Plasma Process., Vol. 2, No. 3, p. 317 , (1982)

9/ Crowe C.T., Sharma M.P., Stock D.E., J. Fluids Eng., p.325, June (1977)

/10/ Proulx Pierre, "Modélisation des écoulements plasma-particules", $\mathrm{Pb}$. D. Thesis, Université de Sherbrooke, (1987).

111/ Shuen J-S., Chen L.-D., Faeth G.M., AIChE Journal, Vol. 29, No. 1, p. 167, (1983)

/12/ Abramovitch G.N., Int. J. Heat Mass Transfer, Vol 14, p. 1039, (1971) 